\title{
LA DIVERSIDAD COMO PROBLEMA
}

\author{
Jordi Garreta \\ Universidad de Lleida
}

\begin{abstract}
RESUMEN. La diversidad cultural es uno de las trazos definitorios de nuestra sociedad. En un contexto, en el que la diversidad -resultado de las migraciones- se va incrementando hay que plantearse una serie de adaptaciones mutuas, más allá de la asimilación. La escuela, institución reflejo de las ideologías dominantes en este sentido, debería tomar en consideración esta diversidad y convertirla en riqueza más que en un problema. Fijándonos en la experiencia del Quebec y otras sociedades que han recibido durante muchos años inmigrantes, consideramos interesante tener en cuenta su experiencia y, por ejemplo, revisar a fondo el material escolar, desarrollar la figura del mediador (un profesional que puede incrementar la comunicación entre centro y familia, relación que se ve influenciada por barreras lingüísticas, socioeconómicas, culturales e institucionales); etc.

ABSTRACT. The cultural diversity is one of the lines of definition of our society. In a context, in the one that the diversity -for the migrations- it leaves increasing it is necessary to think about mutual adaptations, beyond the assimilation. The school, reflective institution of the dominant ideologies in this sense, it should take in consideration this diversity and to transform it into wealth more than in a problem. Noticing the experience of the Quebec and other societies that have received during many years immigrants, considers interesting to keep in mind their experience and, for example, to thoroughly revise the school material, to develop the mediator's figure (a professional that it can increase the communication among centre and family, relationship that is influenced by linguistic, socio-economic, cultural and institutional differences); etc.
\end{abstract}

\section{Clase social, género y etnia como fuentes de desigualdad}

Como afirma M. Fernández Enguita (1995) la escuela presenta la apariencia de un sistema único con forma piramidal: en el que por la base entran y donde van siendo seleccionados. Esta selección supone que se va configurando el "destino" escolar y, también, la futura división social -la obtención de un título académico u otro, comporta la posibilidad de acceso a un determinado mercado laboral. En un marco como el descrito, debemos interrogarnos sobre los factores condicionantes del fracaso y el éxito escolar (en nuestro caso, más allá de la capacidad y esfuerzo de cada alumno). Parece establecido que existe influencia entre el origen social y el origen cultural (lenguaje, "capital cultural", expectativas sociales y escolares, actitudes del alumno y de la familia, etc.). Para Fernández Enguita (1997), entendiendo que en nuestra sociedad las desigualdades más importantes son las de clase, género y etnia, afirma que aunque se trata de realidades distintas y necesitan diferentes tratamientos, los obreros, las mujeres y las minorías étnicas presentan paralelismos: primero, fueron simplemente 
excluidos de unas escuelas no pensadas para ellos; en segundo lugar, fueron escolarizados de forma segregada; $y$ en tercer lugar, se incorporaron a las escuelas llamadas "ordinarias", aunque también es cierto que no con idénticas oportunidades (de ahí, por ejemplo, la necesidad de programas compensatorios que inicialmente se dirigían al conjunto del alumnado desfavorecido y que, poco a poco, se han especializado en las minorías étnicas -es decir, alumnado gitano y de origen inmigrante).

Para acercarnos a la importancia del origen social, sólo es necesario consultar algunos estudios realizados. Entre ellos, el de Quim Casal y otros autores (1994) que analizando el éxito y el fracaso escolar en Cataluña (con una amplia muestra de 2561 alumnos de enseñanza primaria y secundaria) establecen una tipología que relaciona el origen familiar y la producción escolar: familias acomodadas (aproximadamente el $5 \%$ ) donde se sobrerepresentan los alumnos excelentes y medianos; nuevas clases medias (38\%) grupo que concentra la mayoría de alumnos excelentes (bien adaptados y con buenas notas); clases trabajadoras $(40 \%)$ que equilibran la presencia de alumnos que Ilaman problemáticos (mal rendimiento y problemas relacionales) y mediocres (pocas expectativas); y familias desestructuradas (10\%) con alta presencia de alumnos con fracaso escolar. Además, hay que decir que no se olvidan de la variable territorio, ya que los porcentajes altos de fracaso escolar se concentran en el cinturón industrial de Barcelona, donde reside el mayor número de familias con bajos ingresos económicos, escasa cualificación académica y origen migratorio -pero como afirma Fernández Enguita (1997, p. 107) "se trata de desigualdades de naturaleza distinta. La diferencia consiste en que unas son interterritoriales, otras intraterritoriales (clase, género y etnia). Los primeros son lógicamente menos visibles para los individuos, mientras que las segundas permean la totalidad de su vida cotidiana". El estudio de Casal et alii, tampoco olvida el género, concluyendo que mientras el fracaso escolar tiende a hacerse más interclasista el éxito escolar es predominantemente femenino -pero no debemos olvidar que "destinos profesionales" tienen nuestras alumnas, no los mismos que sus compañeros varones sobrerepresentados en estudios socialmente más "masculinos"1.

En tercer lugar, queremos introducir, enmarcándolo dentro de lo que hemos llamado diferencia cultural, la cuestión de las minorías étnicas, en la que nos centraremos, aunque sin olvidar la clase social y el género. La llegada y sedentarización en los últimos treinta años de inmigrantes -sobretodo de los procedentes del llamado Tercer Mundo, ya que parece que los otros no nos preocupan tanto- $y$, como no, los discursos de respeto a la diversidad cultural que han dominado, han comportado que la escuela tome el sendero de la llamada educación intercultural -más a nivel de discursos que de prácticas-, que ha incluido, igual sin pretenderlo², al colectivo que se ha mantenido más al margen: los gitanos (para los que la variable más influyente en su alejamiento de la escuela parece ser la etnicidad ${ }^{3}$.

1. Evidentemente a pesar de los cambios a los que hemos asistido que han comportado una mayor porosidad..

2. A menudo, parece que ya hubiéramos desistido de actuar respecto a este colectivo ("no hay nada que hacer") y que cuando actuábamos lo hiciéramos sólo para aproximarlos a la escuela y nunca en sentido inverso. Pero en este nuevo enfoque intercultural, se pretende introducir también cambios en la escuela, más allá de la mera compensación.

3. Uno de nuestros recientes estudios -Garreta, J. (1999)- realizado a través de una metodología cuantitativa, encuesta, y cualitativa, entrevistas en profundidad, a gitanos de las provincias de Lleida y Huesca, nos ha permitido detectar su alejamiento actual (sólo una tercera parte de los menores de 25 años, que recorde- 


\section{Diversidad cultural y educación.}

\subsection{Sociedades multiétnicas y multiculturales}

Aunque la socialización tiende a la homogeneización de los individuos que conviven en una sociedad concreta, en su seno se genera una heterogeneidad cultural. En los Estados-nación existe diversidad sobre la base de la religión, la lengua y la clase social, diversidad que se refleja en minorías étnicas y grupos que se diferencian culturalmente. La penetración pasada o actual de grupos de individuos en un Estado-nación con pautas diferentes de instalación, pertenencia, reunificación familiar, etc. (Gundara 1993) conlleva a su vez un incremento de la diversidad ya existente. Así, la dinámica social actual se encuentra entre dos tendencias de signo opuesto. Por una parte, la industrialización, el urbanismo, la mediatización tecnológica y el espectacular avance de los medios de comunicación actúan a favor de una creciente uniformización de la vida colectiva. Por otra parte, hay una explosión de reivindicaciones y una defensa de identidades particularistas. La tensión entre ambas tendencias introduce importantes niveles de inestabilidad y conflicto (Abad 1993; Touraine 1994; Lamo 1995).

"La cultura mundial parece así estar sometida a una triple y contradictoria dinámica. De una parte, la fuerte (imparable?) homogeneización derivada de la racionalización/modernización de costumbres y hábitos, impulsada por la educación formalizada (cada vez más homogénea), los mass-media y la comunicación, o las pautas de trabajo, cuyo origen debe vincularse con la cultura occidental, pero que es ya cosmopolita, mundial y (progresivamente) carente de referencias geográficas concretas. (...) Tendencia que se ve reforzada por procesos de integración política o económica. La circulación de objetos, de personas y de mensajes inevitablemente uniformiza. Pero en contra de esa tendencia uniformizadora, se desarrollan las otras dos. De una parte la creciente afirmación de que las grandes culturas históricas que, no sólo sobreviven, sino que se revitalizan sin excesivas dificultades por debajo de o al lado de la cultura homogénea mundial, y están sometidas a un proceso de autoafirmación creciente paralelo a su adquisición de poder político y económico (...)... la tercera gran tendencia: la fragmentación interna de la cultura occidental que se resiste a verse a sí misma como unidad, a verse desde fuera como las otras se han visto obligadas a hacerlo al confrontar la cultura occidental" (Lamo 1995: 72-72).

En síntesis, además de la diversidad cultural interna, la proximidad geográfica, la movilidad demográfica, la convencionalidad y la arbitrariedad de las fronteras políticas, etc. incrementan la complejidad de las sociedades actuales: multilingües, multiculturales y multiétnicas (Pino 1992).

mos deberían haber finalizado la escolarización básica por obligatoria, la han finalizado -también debemos preguntarnos que sucederá con el alargamiento en edad de esta escolarización si ya no acababan a los catorce-) y futuro (a pesar de los discursos, socialmente aceptados, valorando la educación y el conseguir el máximo nivel, al profundizar aflora la poca valoración de la educación paya que creen que de poco servirá al gitano) respecto a la escuela. A pesar de ello, existen diferencias internas en cuanto a expectativas que pueden consultarse en el citado documento. Expectativas y actitudes que son mucho más heterogéneas en el colectivo de inmigrantes africanos, otro de los colectivos estudiados en esta publicación. Además, como no, el género es influyente, otorgando a las hijas expectativas inferiores, sobretodo entre los gitanos. 
Ante este contexto, debemos referirnos al papel que debe realizar la escuela en la sociedad actual. John Rex (1988) parte de que el mantenimiento de la cultura minoritaria es lo mejor para los miembros adultos de la comunidad, a la vez que hay que involucrarles en la educación suplementaria que, si el curriculum es adecuado, no implica inferioridad. Sus diferencias culturales representan problemas, pero también oportunidades. Los valores culturales de las comunidades minoritarias pueden utilizarse no sólo para promover la diferencia y la separación, sino que pueden ser utilizados como base para la competencia conservando la propia identidad, que proporciona seguridad personal. De acuerdo con Rex (1996), un sistema educativo moderno debe tener tres funciones: selección de individuos (según sus capacidades, que les conducen a posiciones ocupacionales diversas), transmisión de habilidades (necesarias para la supervivencia y el trabajo) y transmisión de valores morales. Esta tercera función conlleva un conflicto en el ámbito privado -Rex, distingue entre espacio público del privado como forma de integrar las diferentes culturas de una sociedad-, pues una parte del proceso de socialización, realizado fuera de la institución educativa, consiste en la transmisión de valores (morales y religiosos). Para John Rex lo importante es mantener la igualdad de oportunidades para todos. Lo que la escuela debería transmitir es lo que llama moral cívica (nivel más general y básico de la moral aceptable por toda la sociedad), mientras que la transmisión de los valores particulares correría a cargo de las instituciones comunitarias (aunque el mismo autor propone la posibilidad de que sea el Estado quien se haga cargo de esta tarea, evitando, claro está, la discriminación).

Por su parte para G. Bourgeault, F. Gagnon, M. McAndrew y M. Pagé (1995), la escuela se encuentra en la frontera entre la esfera pública y la privada, lo que exige una atención especial a las demandas de padres de grupos minoritarios, en especial en lo referente al respeto a sus valores y a la consideración de las especificidades.

"(...) les partisans d'une formation civique, dont nous sommes, proposent que l'éducation dans une société démocratique encourage, non pas l'adhésion unanime à des contenus culturels prédéterminés, mais le développement des dispositions et des capacités que requiert la vie dans une société démocratique libérale, respectueuse de la diversité culturelle et religieuse" (Bourgeault, Gagnon, McAndrew y Pagé 1995: 93).

En definitiva, el no-reconocimiento público y en consecuencia escolar (con todo lo que ello puede implicar) de la diferencia conlleva una desigualdad y un handicap para determinados colectivos. Pero también es necesario debatir y establecer la diferenciación entre esfera pública y privada y las implicaciones de esta. De acuerdo con G. Bourgeault, F. Gagnon, M. McAndrew y M. Pagé (1995), la escuela debería dar respuesta a esta diversidad encontrando un equilibrio entre el deseo, legítimo, de que se tenga en cuenta la diversidad (no sólo cultural) y el papel de la escuela en materia de formación cívica para mantener los principios de base y las habilidades necesarias para reproducir una sociedad democrática (este mantenimiento sería el límite del reconocimiento de la diversidad). De hecho, como presentaremos, cualquier sociedad multicultural se plantea cómo hacer frente a esta situación y los conflictos que esta crea (por ejemplo: delimitación de lo que recae en la esfera pública y en la privada) a nivel social e institucional, en particular. 


\subsection{Sociedades multiculturales y educación}

Para llegar a enfoques interculturales una sociedad debe haber puesto en práctica y superado otros de carácter asimilacionista, integracionista, pluralista, etc. (Tarrow 1990). Aunque es cierto que no todas las sociedades realizan pasos hacia el respeto a la diversidad cultural, aquellos que sí lo hacen siguen, generalmente, las siguientes fases: asimilación (perspectiva monocultural); integración (a través de programas compensatorios); pluralismo cultural (además de transmitir la cultura dominante se tienen en cuenta las culturas y lenguas minoritarias, pero manteniendo las distancias); educación multicultural para todos (extensión del anterior paradigma a los alumnos minoritarios y mayoritarios); e interculturalidad (interacción, enriquecimiento...; afectando, también, a todos). Lo anterior se puede condensar en tres grandes fases: asimilación (a); acomodación (b, c, d); e interculturalidad (e).

La educación intercultural, expresión que es poco utilizada en los países anglosajones, ha tomado forma en Francia y en el Quebec -en este último como respuesta a los "peligros" que intuían en el multiculturalismo en su versión de "mosaico" y como reacción a lo que fue definido como multiculturalismo en el conjunto del Canadá. Pero también es cierto que en ocasiones las dos expresiones definen finalmente una realidad muy parecida. A continuación, por interés personal pero también por tratarse de una sociedad que ha ido forjando -junto con Francia, aunque no con idéntico resultado- el término educación intercultural utilizaremos el Quebec -una sociedad principalmente formada a base de sucesivos flujos migratorios y donde el multiculturalismo es uno de los pilares de su sociedad- como ejemplo de consideración de la diversidad cultural más como riqueza que como problema. Eso sí, refiriéndonos antes a uno de los países más referenciados al tratar este tema, los Estados Unidos, donde también las sucesivas olas migratorias y las actuaciones tomadas para "integrar" a los inmigrantes han ido configurando los modelos dominantes: el asimilacionista (angloconformity), el de crisol (melting-pot) y el pluralista.

La teoría asimilacionista, traducida al discurso educativo, impulsó el desarrollo de la educación monocultural --predominio de la mayoría o grupo dominante, el sistema escolar se consideraba la institución más importante por la que se intentaba conscientemente construir una identidad conformista y reunir a la población de diferentes nacionalidades bajo un referente común (Troyna 1992; Anthias y Yuval-Davis 1993). Posteriormente propuso la sustitución de tal modelo asimilacionista del curriculum americano mediante la introducción de la idea de diversidad cultural. Sirve como síntesis el discurso de N. Glazer (1992) que presenta tres soluciones realizadas en Estados Unidos para solucionar los problemas de la infancia de origen racial, cultural y lingüístico distinto:

1. Dessegregación: consistente en mezclar a los niños. Atacaba la segregación según el color con la intención de romper la dinámica de la educación inferior de los negros y, en consecuencia, la obtención de empleos peores -se suponía que mejorando el empleo y los ingresos, también lo harían las condiciones de vida, como la vivienda, por ejemplo. La segregación de las minorías- afroamericanos en el sur, chinos y japoneses en el oeste, etc.- se compensa mediante esta dessegregación o integración. Los desplazamientos que tenían que hacer los alumnos para asistir a escuelas de su "color" desaparecieron con la creación de zonas escolares basadas en la proximidad, pero esta zonificación no produjo una proporcionalidad entre blancos y negros: la concentración en los barrios de uno sólo de los colores reproducía la segregación en las escuelas. El resultado fue el fracaso de esta política, 
debido a la continuidad de la proporción de colores en las escuelas, a la que contribuyó la decisión de una parte importante de los padres blancos de desplazarse del sistema público al privado (Glazer 1989), lo que se ha venido a llamar la 'huida blanca'.

2. Enseñanza compensatoria para la infancia pobre. Esta política es efectiva para los negros, portorriqueños y americanos de origen mexicano, pero es menos útil para otras categorías que no comprenden a tantos niños y niñas pobres (un ejemplo sería el programa de educación preescolar, Head Start, en los años 60).

3. Programas que tienen en cuenta la lengua y la cultura de las minorías; son los programas bilingües. Estos programas han perdido parte del apoyo político, aunque se mantienen para introducir a los inmigrantes en el habla inglesa.

Durante la década de los 70, los reformadores o intelectuales políticos liberales consiguieron un consenso moral con el Estado para la mejora de las relaciones "raciales" en la educación y la sociedad. Estas actuaciones no tuvieron la misma repercusión sobre las distintas minorías. Así, por ejemplo, mientras que la clase media afroamericana logra beneficios sociales y económicos, otros segmentos o minorías no lo consiguen en el mismo nivel. Un empeoramiento de su situación laboral, principalmente en los centros urbanos de Estados Unidos así como los efectos diferenciales desiguales y asincrónicos provocan la aparición de un nuevo movimiento conservador -neoconservador- por lo que respecta a las políticas educativas y sociales (MacCarthy 1994; Carnoy 1994).

"Este discurso considera a los norteamericanos blancos, en especial a los varones, como las nuevas víctimas de la 'discriminación al revés' provocada por las erróneas políticas estatales que favorecen a las minorías". (MacCarthy 1994).

En el ámbito educativo se insiste en privilegiar el éxito académico y no la promoción de la equidad. Se inclinan por políticas "ciegas al color" y en contra de la porosidad de la cultura dominante. Se afirma que las políticas liberales anteriores provocaban el efecto perverso de desanimar los esfuerzos y reducir el aprovechamiento de los jóvenes pertenecientes a minorías étnicas. En esta línea neoconservadora, los nuevos planes de educación de los años 90, en lo que se refiere a las relaciones "raciales", destacan cuatro actuaciones": fin de las preferencias de las minorías, como la discriminación positiva; fin de la suavización del curriculum escolar introduciendo por motivos políticos materias como los estudios étnicos o la educación multicultural; reintroducción de un núcleo curricular que destaque valores estéticos, sociales, intelectuales y morales deseables; y introducción de programas exigiendo el trabajo de las minorías y no el aprovechamiento de las condiciones favorables (MacCarthy 1994). Sin embargo, el debate interno, como se ha dicho, existe. Ante los que quieren la supresión de la acción afirmativa, hay colectivos e intelectuales que siguen los discursos compensatorios o reparadores de discriminaciones sufridas -justicia distributiva (ver Samper 1999). Si queremos tener una visión de conjunto de la evolución realizada en EUA y, al mismo tiempo, conocer los principales modelos de integración de

4. "Muchos de estos argumentos neoconservadores se han incorporado ya a las propuestas políticas en los niveles federal, estatal y local de la Administración y de las decisiones educativas" (MacCarthy 1994: 115). 
las minorías étnicas y su implicación a nivel de cultura, estructura social e identidad, sólo hay que ver el cuadro que sigue.

Cuadro 1. Modelos teóricos de integración de las minorías étnicas.

\begin{tabular}{llll}
\hline \multirow{2}{*}{$\begin{array}{l}\text { MODELO DE } \\
\text { INTEGRACIÓN }\end{array}$} & $\begin{array}{l}\text { PAUTAS } \\
\text { CULTURALES }\end{array}$ & $\begin{array}{l}\text { ESTRUCTURA } \\
\text { SOCIAL }\end{array}$ & $\begin{array}{l}\text { IDENTIDAD } \\
\text { COLECTIVA }\end{array}$ \\
\cline { 2 - 4 } ASIMILACIÓN & $\begin{array}{l}\text { Pérdida de pautas } \\
\text { culturales propias y } \\
\text { adquisición de las de } \\
\text { la nueva comunidad }\end{array}$ & Inserción igualitaria & $\begin{array}{l}\text { Pérdida de la propia } \\
\text { identidad y sentimiento } \\
\text { de pertenencia a la } \\
\text { nueva comunidad }\end{array}$ \\
\hline MELTING POT & $\begin{array}{l}\text { Creación de una nueva } \\
\text { cultura por fusión de }\end{array}$ & $\begin{array}{l}\text { Inserción igualitaria } \\
\text { en la nueva estructura }\end{array}$ & $\begin{array}{l}\text { Surge nueva } \\
\text { identidad colectiva }\end{array}$ \\
\hline PLURALISMO & $\begin{array}{l}\text { No se cambian pautas } \\
\text { CULTURAL }\end{array}$ & $\begin{array}{l}\text { Inserción igualitaria } \\
\text { en la estructura de la }\end{array}$ & $\begin{array}{l}\text { Dualidad entre la } \\
\text { identidad originaria y } \\
\text { la pertenencia a la }\end{array}$ \\
& & sociedad de adopción & $\begin{array}{l}\text { la peras } \\
\text { nueva comunidad }\end{array}$ \\
\hline
\end{tabular}

Fuente: BLANCO 1990: 76.

Otro país que nos ha interesado es Canadá y, especialmente, Quebec ya que ha apostado, dentro del multiculturalismo canadiense, por el interculturalismo, eso sí después de realizar una evolución. Para M. McAndrew i J. Rossell (2001) en la política de integración escolar y de educación intercultural se pueden distingir tres fases que se corresponden con la dinámica identificada en otros contextos por Banks y Lynch (1986): a) la diversidad cultural producida por las sucesivas migraciones se percibe como un problema lingüístico; b) se cree necesario reconocer y valorar la diversidad lingüística y cultural; c) se realiza la adaptación institucional al pluralismo -que los autores coinciden en afirmar que todavía no ha acabado.

Seguramente muchas de las cuestiones y retos que aparecen en otro contexto, no nos son desconocidas en España. La diversidad que tienen en sus aulas, años antes de nuestro despertar a estas cuestiones, lleva a que se planteen una serie de soluciones para cohesionar una sociedad culturalmente diversa, formada por sucesivas olas migratorias y donde los que tienen un papel subordinado son los llamados autóctonos (amerindios e inuit). Estas actuaciones, realizadas a partir de los setenta pero sobretodo los ochenta y noventa, indican la evolución, que toda sociedad hace, hasta llegar a plantearse un modelo de educación intercultural ${ }^{5}$. Estos pasos y las políticas e intervenciones implementadas pueden orientar los pasos de los próximos años en nuestro

5. Eso sí, aún en la actualidad creen no haber llegado a la situación ideal y ya están hablando de educación a la ciudadanía, concepto más amplio, que incorporaría al primero y que trataría de evitar los problemas de trabajar las diferentes culturas: por ejemplo, la diferenciación en función de estas, efecto, por supuesto, no deseado. 
contexto, eso sí, teniendo muy en cuenta los errores cometidos y evaluando hacia donde queremos dirigirnos en la solución del "problema" de la diversidad -que sea visto como un "problema" y que genere tanta preocupación por parte de los diferentes agentes educativos con el reducido volumen relativo, comparativamente, que supone en nuestra sociedad y, en particular, en nuestras aulas les podría parecer hasta ridículo a los canadienses, estadounidenses...-. El considerarlo "problema" más que una riqueza ya nos diferencia inicialmente.

Si tuviéramos que situar el momento a partir del cual la administración del Quebec empieza a hablar de educación intercultural tenemos que remontarnos al año 1983. Esta mención comportará la revisión de los materiales pedagógicos, nueva formación para el profesorado y la reflexión sobre el papel que debe tener la escuela en la sociedad. A partir de ese momento se toman diferentes medidas en esta dirección. En concreto, destacaríamos las sucesivas revisiones de los materiales pedagógicos, la formación inicial y continua del profesorado, los cursos de sensibilización, la creación de agents de liaison y de agents de milieu (que podemos traducir como mediadores interculturales, a pesar de que habría que definir de quien se trata), la introducción de estrategias de negociación y de resolución de conflictos, la potenciación del aprendizaje cooperativo y, especialmente, el proceso, recientemente iniciado, de desconfesionalización del sistema educativo. A pesar de ello no se considera que sea suficiente ya que existen algunas lagunas importantes: se constata que en los materiales aún existe la imagen del "nosotros" frente a los "otros" que dificulta la construcción de una identidad quebequesa plural; hay resistencias entre el profesorado; imágenes mutuas no coincidentes entre padres y profesionales que dificultan la relación; la participación en la escuela de algunos padres no es la óptima y la figura del profesional que debería potenciarla (que hemos traducido, para englobar la diversidad, como mediadores) está desapareciendo sobre todo por efecto de la limitación presupuestaria... (ver Garreta 2000).

En la práctica, el gobierno de Quebec ha promocionado sobre todo el valor lingüístico, dejando en segundo y tercer lugar el reconocimiento de que es una sociedad democrática y pluralista y la educación intercultural. Los discursos más recientes consideran que, para avanzar en la dirección de la educación intercultural, se debe construir un espacio cívico común y un verdadero diálogo intercultural entre los miembros de la sociedad, buscando armonizar las diferentes contribuciones. Desde hace algunos años, sin dejar de referirse a la educación intercultural, se insiste en el concepto más amplio de ciudadanía y, en consecuencia, se refieren a la éducation à la citoyenneté. Dentro de este concepto se incluye también la educación intercultural, entrando en una relación de complementariedad, pero para conseguirlo, en la escuela y en la formación del profesorado, se debe explicar el contenido de la cultura cívica de forma que refleje un estado de derecho democrático, igualitario y pluralista.

\section{Los problemas que genera la diversidad cultural}

Parece evidente, por la entrada de determinados colectivos anteriormente excluidos o segregados del sistema educativo o por inmigración, que el incremento de la diversidad cultural genera una serie de situaciones a las que el conjunto de agentes educativos presentes en los centros escolares deben hacer frente. Algunos de estos retos son muy evidentes, otros parecen pasar por alto. Un estudio realizado en Canadá nos permite presentar el complejo entramado de cuestiones a tener presentes. El tra- 
bajo, realizado con personal de las escuelas y los padres de diferentes comunidades culturales, permite diferenciar cuatro grupos de dificultades en la comunicación escuela-familia (Hohl 1991; 1996) a las que deberíamos añadir las que aparecen dentro del aula y que a menudo se derivan de las siguientes:

- Las barreras lingüísticas: comunicación imposible (conocimiento insuficiente o nulo de la lengua de enseñanza por parte de algunos padres; dificultad por parte de las escuelas en tener servicios de interpretación); comunicación limitada (conocimiento insuficiente de los padres de los procedimientos y necesidades de cada una de las partes, en estos casos la comunicación se limita a la simple transmisión de información sobre los reglamentos, las notas, la agrupación y los problemas de comportamiento).

- Las barreras socioeconómicas: no disponibilidad de algunos padres por las condiciones de vida precarias, horarios de trabajo...; nivel de escolarización insuficiente para poder ayudar en los estudios de los hijos; poco interés o escasa motivación por participar en la vida de la escuela al no tratarse de una prioridad.

- Barreras culturales: diferencia de los sistemas escolares (no es igual el que conocen los padres que el que encuentran en destino, las divergencias pueden alcanzar: valores educativos privilegiados, reglamento, horarios, personal no docente que en otros países no existe -enfermero, trabajador social...-, programas de estudios, métodos de evaluación, formas de relacionarse escuela y familia, rol de la escuela y estatuto del personal docente, etc.); diferencia entre valores familiares de la sociedad de acogida y los de la sociedad de origen: estructura familiar (importancia o no de la familia extensa), roles en el interior de la familia (por ejemplo importancia o no de los abuelos), diferencia entre valores educativos privilegiados (respecto al cuerpo, la autoridad y la disciplina).

- Las barreras institucionales: dificultad de algunos padres de percibir el personal de la escuela como agentes educativos competentes y considerar la escuela como un lugar accesible y donde tienen el derecho y deber de participar; dificultad de que la escuela traspase lo estrictamente escolar por la actitud cerrada que manifiestan padres y algunos profesores.

De entre todas estas barreras, queremos destacar, en primer lugar, por su grado de abstracción, la que erigen por ambas partes, familia y profesorado, en función de lo que cada uno espera del otro. En efecto, uno de los frenos que mitigan la interacción entre padres y educadores procede de la diferencia, como bien ha señalado Janine Hohl, que existe entre los padres reales y el modelo de padres que quiere y que se construye la propia escuela. Centrándose en un colectivo de padres analfabetos (haitianos y salvadoreños) Hohl observa que éstos no conocen las reglas ni lo que se espera de ellos, y mucho menos la definición institucional de sí mismos. En el momento que tienen que enfrentarse a la cuestión educacional proyectan sus imágenes preconstruidas y lo que esperan de la escuela; pero es entonces cuando se hace evidente la separación que se abre entre lo que realmente se les pide y se espera de ellos y lo que este colectivo entiende que debe representar. Sus niveles de incomprensión del hecho escolar se centran en lo que es la escuela (funcionamiento, estructura, objetivos, etc.), en las dificultades escolares que tienen sus hijos, en la incapacidad de ayudarlos y muy a menudo en la reducción de la comunicación con el profesorado. "Face aux difficultés scolaires, l'école s'adresse pourtant fréquemment aux familles pour requérir un soutien direct à l'apprentissage, comme 
si les parents pouvaient tout 'naturellement' se substituer aux enseignants et réussir là où ces derniers échouent" (Hohl 1996b). Así pues, es patente la distancia entre la imagen de los progenitores reales y la que se construye de ellos la propia escuela. Pero este alejamiento entre la visión tecnocrática del rol de los padres y las colaboraciones que realizan éstos en el centro escolar no implica que el discurso oficial sea poco importante o que no tenga ningún efecto. Al contrario, contribuye a desarrollar, especialmente en los contextos menos favorecidos, una visión de la familia y de los padres en términos de déficit, de inadecuación y poco interés por la escuela, fundada en imágenes estereotipadas del fracaso escolar. A partir de los estereotipos se construyen las exigencias que se realizan a los padres. El padre "ideal" debería apoyar y ayudar al desarrollo de los objetivos escolares, estar de acuerdo con las normas sociales y culturales... La convicción de que la escuela no tiene nada que hacer si la familia no asume "sus responsabilidades", sobre todo con alumnos con fracaso escolar, procede de estas imágenes estereotipadas que posee el profesorado. Las entrevistas realizadas a dichos padres analfabetos muestran la fractura existente entre las expectativas del profesorado, con su imagen de los progenitores, y los padres, preocupados por el éxito escolar y laboral de sus hijos, y, por otro lado, las condiciones reales cotidianas y las competencias objetivas de estos padres y, en consecuencia, las de sus hijos

En segundo lugar, complemento de lo anterior, encontramos las resistencias que aparecen en la administración y otros agentes educativos al abordar la diversidad cultural. Janine Hohl (1996b) las divide en dos grandes categorías, según el efecto directo o indirecto en los inmigrantes: la resistencia que se genera entre los cargos de la administración, políticos, consejeros e investigadores, y la del profesorado, que tiene una relación directa con este alumnado y sus padres. Los primeros realizan mediaciones administrativas o académicas que los llevan a distanciar su persona, sus creencias, sus ideas, sus argumentaciones de los grupos a los que se dirigen. El profesorado está mucho más "expuesto" e implicado con estos colectivos. Así por una parte, se elabora un discurso entre los administradores, investigadores, consejeros pedagógicos y consejeros políticos y, por otra, el profesorado desarrolla una representación propia de su rol. La toma de decisiones y el trabajo cotidiano que conlleva el contacto directo con el alumnado y los padres generan incertidumbre y ansiedad en el profesorado, que se acentúan cuando desarrollan su labor en contexto pluriétnico y deben enfrentarse a valores que no comparten con los padres. A veces el comportamiento de estos últimos resulta difícil de comprender por parte de los profesores y además pueden surgir conflictos de valores como, por ejemplo, las relaciones que se establecen entre hombres y mujeres, el no reconocimiento del estatuto profesional del profesorado (por ser mujeres), el concepto de que el hijo es un sujeto con derechos y es libre de realizar sus elecciones y tomar decisiones, percepciones divergentes del proceso de aprendizaje, el no uso de una lengua común para comunicarse, etc. Algunos de estos aspectos chocan con la identidad del profesorado y ahí es cuando para preservar sus esquemas oponen resistencia. También es cierto que no todo el profesorado responde al mismo perfil, pero la autora nos descubre que estas representaciones son muy frecuentes.

6. Para estos inmigrantes la misión escolarizadora tiene que prevalecer, mientras que la socializadora tiene que quedar subordinada. Insisten en la pertinencia y la legitimidad de una aproximación autoritaria de los aprendizajes y en la importancia de que cada niño asuma individualmente la responsabilidad de su futuro escolar y profesional. 
En síntesis, D. Helly (1996), como otros, afirma que en general existe la necesidad de incrementar el interés por la participación de los padres en la escuela, con todo lo que ello implica de conocimiento y acercamiento a la misma. En Quebec se presta especial atención a la participación de los padres en la escuela -así por ejemplo cada vez se les otorga más poder en los centros educativos, como muestra la reforma que han llevado a cabo- y al estudio de los factores que intervienen en ella, así como las resistencias que genera el profesorado ante la diversidad étnica y cultural. Con la intención de aproximar estos dos colectivos, ha surgido una figura "profesional" que, bajo diferentes nombres y grados de implicación, se dedica a la misión de mediación. Tal interés se debe contextualizar con la dirección tomada en esta provincia canadiense, en línea de lo que se ha llamado educación intercultural y que se ha caracterizado, entre otras cuestiones, por el análisis de los recursos pedagógicos y las sucesivas revisiones de los materiales y la formación del profesorado, la lucha contra la discriminación y el racismo, etc.

Con la intención de mejorar las relaciones entre escuela y progenitores, garantizar la igualdad de oportunidades de todos los alumnos y democratizar los centros docentes se han creado en diferentes ciudades canadienses (Toronto, Vancouver y Montreal) unas figuras profesionales que en España se han convenido en Ilamar mediadores interculturales. A. Beuachesne (1987) que estudia a estos profesionales, reconoce que este proyecto es la respuesta a la dificultad que tiene la organización escolar para adaptar su currículum y sus servicios a las necesidades de unos usuarios cada vez más diversos, particularmente en contextos económicamente desfavorecidos o pluriétnicos. A los problemas de comunicación lingüística del alumnado y de los padres, hay que sumar las dificultades de gestionar esta diversidad en el conjunto de actividades escolares y en el aula. Los resultados del estudio de Beauchesne indican que la naturaleza y la urgencia de las necesidades por las que se crearon estas figuras profesionales implican cambios en profundidad en el contexto escolar, especialmente la adaptación del currículum escolar a las necesidades de los usuarios a través de la creación de vías de comunicación entre escuela y comunidad, en particular entre padres y escuela. Pero a pesar de las coincidencias, estas ciudades distinguen las funciones de estos profesionales a través de las demandas e intervenciones que deben realizar. A esto hay que añadir que tales funciones se encuentran muy subordinadas a las necesidades y exigencias de las escuelas. Algunas intervenciones como la traducción de mensajes, la promoción de la participación en actividades paraescolares..., limitan su participación y la convierten en meramente instrumental para resolver tan sólo los problemas de funcionamiento. En un contexto así, resulta periférica la resolución del verdadero problema: abordar la cuestión del rol de los padres en el trabajo de adaptación del currículum escolar a las necesidades de la diversidad existente.

M. McAndrew y J. Y. Hardy (1992), centrados sólo en Quebec, concluyen que se desprende un efecto muy positivo de las actuaciones de las figuras. También, más recientemente, se han juzgado estas intervenciones (Helly 1996) como muy eficaces a pesar de que aparecen los diferentes modelos mal definidos y que se alargan los problemas a resolver por ser dependientes de los diferentes profesionales de la escuela. Para M. McAndrew (1993), la utilidad de los agentes está ampliamente reconocida durante los años noventa, gracias a las oficinas especiales que existen en escuelas donde al menos el $25 \%$ pertenece a minorías culturales, lo que permite favorecer el desarrollo de relaciones armoniosas entre padres y escuela. Otra cuestión es que, 
como nos comentaba la propia M. McAndrew y también J. Hohl, estas figuras están desapareciendo por efecto de las limitaciones presupuestarias.

Para relacionarlo con nuestro contexto, el incremento de funciones atribuidas al profesorado (parece que este deba resolver muchos de los problemas de nuestra sociedad: violencia, racismo...; agregando carga al pesado fardo que ya porta este colectivo y al que en general poco reconocimiento social se brinda) tampoco se encuentra exento de resistencias (resistencia a asumir lo que creen que no les toca, a aceptar cambios en el funcionamiento, etc.). Tampoco debemos olvidar la presencia de representaciones de la alteridad -imágenes, expectativas, que se tienen de los alumnos y de los progenitores ${ }^{7}$ - y la transmisión de estas -étnicas, de género y de clase- a las futuras generaciones. Pero evidentemente, no sólo el profesorado es el reflejo de las representaciones sociales, los libros de texto también cuentan, a pesar de las mejoras, con esos sesgos (Garreta 1999a).

En Quebec, en los últimos años se han realizado importantes esfuerzos para crear materiales pedagógicos, a menudo producidos por el Ministère de l'Éducation, para la sensibilización y el perfeccionamiento del profesorado: guías de recursos en educación intercultural, cuadernos para los formadores, guías de actividades sobre educación intercultural, derechos de la persona y valoración de las aportaciones de las minorías a Quebec, vídeos, juegos étnicos, etc. La revisión de los contenidos se consideró y considera uno de los primeros frentes en el avance hacia la educación intercultural, las diferentes disciplinas y los recursos pedagógicos deben tener en cuenta y valorar la aportación de la diversidad etnocultural. La diversidad étnica y cultural exige la revisión de los contenidos de la enseñanza y de los recursos pedagógicos con un nuevo enfoque que permita identificar las omisiones, las tendencias explícitas o implícitas, los estereotipos, etc. En este sentido, uno de los primeros pasos que no se puede soslayar es aceptar a cada alumno como miembro de un grupo particular, pero a su vez como un ser humano que vive en una sociedad concreta, con todo lo que esto implica. De esta forma, la escuela debe descubrir la diversidad cultural que hay en la humanidad. Por ejemplo, se afirma que es necesario que el alumnado de las escuelas de Quebec comprenda la diversidad que caracteriza a su sociedad y que forma parte de su vida. Esta comprensión y reconocimiento es una forma de legitimación. Pero también debe verse a cada individuo como individuo, no como un producto de una cultura étnica determinada, y destacar lo que une a los individuos más que lo que les separa. En esta labor todas las disciplinas pueden ayudar: arte, matemáticas, ciencias humanas, etc.

En España, se ha mostrado cierto interés por analizar los libros de texto, y aunque no son muy numerosos los estudios, las líneas de investigación se han focalizado en torno a datos cuantitativos o bien cualitativos, por regla general se centran en los contenidos transmitidos, las imágenes en las que se apoyan y en el lenguaje utilizado. Ya el conocido estudio de T. Calvo (1989) sobre los libros de texto detectaba, entre otras cosas, la casi no presencia de los gitanos (eran ninguneados en los textos); la dominación del espacio y el etnocentrismo localista era el criterio orientador más importante en la construcción de las identidades y el tratamiento de la unidad y la diversidad cultural en España; y, en cambio, el mayor espacio otorgado al tratamiento de los problemas raciales en otros países, particularmente los Estados Unidos... Éstas, y otras

7. A su vez estos se construyen una imagen del profesorado y lo que este espera de ellos. Imagen y realidad no tienen porque coincidir. 
constataciones ponían de manifiesto que los problemas sociales se situaban, generalmente, "fuera". Trabajos más recientes, como el de J. García y A. Granados (1998), constataba que: los contenidos insisten en señalar las diferencias físicas y de otros elementos -alimentación, vestimenta...- como una forma de mostrar las diferencias entre individuos. Los autores consideran que no hay duda de que muchos de estos textos intentan igualar diversidad a riqueza, pero también es cierto que la situación descrita limita sensiblemente los efectos que puedan obtener esos intentos. Hay que decir que a pesar de que ciertos autores y editoriales se están haciendo eco de la demanda de material didáctico y textos, aún se considera que lo existente no responde a las necesidades de la escuela; muchos creen que aún es necesario trabajar fecundamente en esta dirección.

En síntesis, del currículum (Fernández Enguita 1995) depende el paso de la igualdad formal a la igualdad real. Las representaciones -en el currículum formal y en el oculto, en este último la lenta transmisión le hace más resistente al cambioexistentes (también fruto de otros agentes de socialización; no olvidemos a los medios de comunicación que contribuyen a la construcción y afirmación de imágenes; por ejemplo la inmigración como problema, como sinónimo de "peligro", de delincuencia, etc.; ver Samper 1996); las distancias creadas; la falta o limitación de la comunicación y la inexistencia de canales que la mejoren;... se convierten en obstáculos -no infranqueables- a superar para conseguir realmente un modelo educativo que respete y valore la diversidad cultural. Es decir, que iguale la diversidad cultural a riqueza y no a problema.

\section{Referencias Bibliográficas}

ABAD MÁRQUEZ, L. (1993). "La educación intercultural como propuesta de integración". En ABAD, L., CUCO, A y IZQUIERDO, A.: Inmigración, pluralismo y tolerancia. Madrid, Ed. Popular, 11-69.

ANTHIAS, F. y YUVAL-DAVIS, N. (1993). Racialiced boundaries. London, Routledge.

BANKS, J.A. y LYNCH, J. (1986). Multicultural Education in Western Sociey. Londres, Boston, Sydney, Toronto, Holt, Rinehart and Winston.

BEAUCHESNE, A. (1987). Les agents de liaison de Montréal, Toronto et Vancouver. Sherbrooke, Faculté d'Éducation, Éditions du CRP.

BLANCO, C. (1990). La integración de los inmigrantes en Bilbao. Bilbao, Ayuntamiento de Bilbao, Colección Estudios Bilbainos, Bilbotar Ikaskuntza Sorta.

BOURGEAULT, G; GAGNON, F.; McANDREW, M. y PAGE M. (1995). "L'espace de la diversité culturelle et religieuse à l'école dans une démocratie de tradition libérale", Revue Européenne des Migrations Internationales, , Vol. 11, no 3.

CALVO, T. (1989). Los racistas son los otros. Madrid, Editorial Popular.

CARNOY, M. (1994). Faded Dreams. The Politics and Economics of Race in America. Cambridge, Cambridge University Press.

CASAL, J. et alii (1994). Éxit i fracàs escolar a Catalunya. Barcelona, Fundació Jaume Bofill. 
FERNÁNDEZ ENGUITA, M. (1995). La escuela a examen. Madrid, Pirámide.

FERNÁNDEZ ENGUITA, M. (1997). "Los desiguales resultados de las políticas igualitarias: clase, género y etnia en la educación". En Fernández Enguita, M. Sociología de las instituciones de educación secundaria. Barcelona, ICE/Horsori, 107-122.

GARCÍA CASTAÑO, J. y GRANADOS MARTÍNEZ, A. (1998). "Racialismo en el currículum y en los libros de texto. La transmisión de discursos de la diferencia en el currículum oficial de la comunidad autónoma andaluza y en los libros de texto de la educación primaria". En BESALÚ, X., CAMPANI, G. y PALAUDÀRIES, J.M. (comp.) La educación intercultural en Europa. Un enfoque curricular. Barcelona, Pomares-Corredor, 181-209.

GARRETA, J. (1999). La integració en l'estructura social de les minories ètniques. Lleida, Universidad de Lleida.

GARRETA, J. (1999a). "La diversidad cultural en los manuales escolares: crónica de una selección y revisión necesarias". En ESSOMBA, M.A. (coord). Construir la escuela intercultural. Reflexiones para trabajar la diversidad étnica y cultural. Barcelona, Graó, 133-142.

GARRETA, J. (2000). Diversidad cultural y educación en Quebec. Lleida, Milenio.

GLAZER, N. (1989). "The education and Housing of Ethnic Minorities in the United States", en Revue Européenne de Migrations Internationales, Volume 5 № 1, 75 84.

GLAZER, N. (1992). "Etats-Unis: Une immigration permanente". En WIHTOL, C. y CHARTIER, A.M. Ecole et intégration des immigrés a Problèmes politiques et sociaux $n^{\circ}$ 693. Paris, La documentation Française, 47-51.

HELLY, D. (1996). Le Québec face à la pluralité culturelle, 1977-1994. Québec, Presses de la Université du Laval.

HOHL, J. (1991). Singulier/pluriel. Montréal. Montréal, Conseil Scolaire de l'île de Montréal.

HOHL, J. (1996). "Résistance à la diversité culturelle au sein des institutions scolaires". En GAGNON, F., MCANDREW, M. y PAGÉ, M. Pluralisme, citoyenneté \& Éducation. Montréal, Harmattan.

HOHL, J. (1996b) "Qui sont 'les parents'? Le rapport de parents immigrants analphabètes à l'école', Lien social et politiques (RIAC), Montréal, Institut National de la Recherche Scientifique.

JORDAN, J. A. (1998). Multiculturalisme i educació. Barcelona, Proa.

McANDREW, M. (1993). L'intégration des élèves des minorités ethniques quinze ans après l'adoption de la loi 101: quelques enjeux confrontant les écoles publiques de langue française de la région montréalaise, document de réflexion soumis à la Direction des études et de la recherche. Montréal, Ministère des Communautés Culturelles et de l'Immigration de l'Éducation.

MacCARTHY, C. (1994). Racismo y curriculum. Madrid, Morata. 
MCANDREW, M. y ROSSELL, J. (2001). Immigración y educación intercultural en Quebec: programas y debates. Montreal, Université de Montréal, no publicado.

McANDREW, M. y HARDY, J. Y. (1992). Les agents de liaison et les agents de milieu. Un bilan. Montréal, Université de Montréal, no publicado.

LAMO de ESPINOSA, E. (1995). "Fronteras culturales". En LAMO de ESPINOSA, E. (Ed.). Culturas, estados y ciudadanos. Una aproximación al multiculturalismo en Europa. Madrid, Alianza editorial, 13-79.

PINO ROMERO, A. (1992). "La educación intercultural ante las diferencias étnicas, diferencias culturales y procesos de aculturación. Problemática de la identidad cultural en sociedades multiculturales. Emigración y educación intercultural". En VVAA. X Congreso Nacional de Pedagogía. Salamanca, 153-168.

REX, J. (1988). The ghetto and the underclass. Essays on Race and Social Policy. Vermont, Gower Publishing Company.

REX, J. (1996). Ethnic minorities in the modern nation state. Working papers in the theory of multiculturalism amd political integration. London, Macmillan Press LTD.

SAMPER, L. (1996). "Etnicidad y curriculum oculto: la construcción del 'otro' por los futuros educadores". En Solé, C. (edit.). Racismo, etnicidad y educación intercultural. Lleida, Universitat de Lleida, 63-100.

SAMPER, L. (1999). "Estratificación étnica y acción positiva. El caso de California", Revista Internacional de Sociologia $\mathrm{n}^{\mathrm{o}}$ 22, 203-228.

TOURAINE, A. (1994). "Inmigración: ¿Problema étnico o problema social?". En BERGALLI, R. y CASADO, D. Frente a la sociedad dual. Jornadas sobre pobreza y marginación. Barcelona, Editorial Hacer, 189-229.

TROYNA, B. (1992). "Can you see the join? An historical analysis of multicultural and antiracist education policies". En GILL, D., MAYOR, B. y BLAIR, M. Racism and education. Structures and strategies. London, SAGE publications, 63-91. 